\title{
EL DEFENSOR DEL PUEBLO Y SUS RELACIONES CON LAS CORTES GENERALES
}

\author{
JOSÉ MARÍA CODES CALATRAVA \\ Letrado de las Cortes Generales
}

\author{
SUMARIO \\ I. Introducción. \\ II. Nombramiento y cese del Defensor del \\ Pueblo. \\ III. La presentación de los Informes del De- \\ fensor del Pueblo. \\ IV. Los medios personales, materiales y eco- \\ nómicos del Defensor del Pueblo. Otros \\ aspectos de sus relaciones con las Cortes \\ Generales. \\ V. Reflexiones finales.
}

\section{INTRODUCCIÓN}

La Constitución configura al Defensor del Pueblo como el Alto Comisionado de las Cortes Generales, designado por éstas para la defensa de los derechos comprendidos en el Título Primero, para lo que podrá supervisar la actividad de la Administración, dando cuenta a aquéllas de su labor. Sobre esta relación, que como señala La Pergola ${ }^{1}$ se presenta constantemente aunque sea susceptible de graduaciones, existe una abundante literatura. Con este trabajo pretendemos abordar sumariamente los principales aspectos en los que ambas instituciones encuentran puntos de contacto. Todo ello se intentará hacer desde un punto de vista eminentemente práctico, aunque, lógicamente, con las necesarias referencias doctrinales. Por ello, nos ceñiremos a lo que tiene que ver con el nombramiento y cese del Defensor del Pueblo y de sus Adjuntos, con la presentación de los Informes del Defensor del Pueblo y con la

1 LA PERGOLA, Ombudsman y Defensor del Pueblo: apuntes para una investigación comparada. En Revista de Estudios Políticos, n. ${ }^{\circ}$ 7, 1977, pág. 79.

UNED. Teoría y Realidad Constitucional, núm. 26, 2010, pp. 389-410. 
configuración legal del personal al servicio del Defensor del Pueblo. Tendremos de esta manera una visión panorámica de las circunstancias en las que el Defensor del Pueblo y las Cortes Generales realizan actuaciones convergentes o entran en contacto por cuestiones organizativas.

Antes de ello, parece oportuno ofrecer de forma previa una relación de las diversas posiciones doctrinales sobre la naturaleza jurídica de la relación entre el Defensor y las Cortes Generales.

Las discusiones en torno a la configuración de la institución se produjeron ya durante el propio proceso constituyente. Como señala Garrido Falla ${ }^{2}$, algunos parlamentarios mostraron sus dudas al respecto de la redacción del artículo 54. Especialmente expresiva es la frase de Martín-Retortillo, que afirmó que uel precepto tal como está redactado es un híbrido, que no se sabe a dónde va, es una institución que se ha regulado de una manera aturullada que, sin duda alguna, está condenada al fracaso".

La Constitución utiliza el término "Alto Comisionado de las Cortes Generales", lo cual en un primer momento puede llevar a pensar que el Defensor del Pueblo es un simple mandatario del Parlamento español. La doctrina opina que no estamos ante una caracterización tan sencilla. Para Álvarez Conde $^{3}$, de su proceso de nombramiento y de su status jurídico puede deducirse una cierta dependencia al inicio del ejercicio del cargo de las Cortes Generales, pero por otro lado el Defensor del Pueblo ejerce sus funciones con autonomía, la cual se encuentra únicamente mediatizada por depender presupuestariamente de las Cortes Generales, así como de la necesidad de presentar ante las mismas su Informe Anual. En cualquier caso, para este autor el Defensor del Pueblo no puede ser considerado como una prolongación del Parlamento. En una línea similar se manifiesta Sáinz Moreno ${ }^{4}$, que con si habitual brillantez afirma que si bien el Defensor del Pueblo es un "órgano auxiliar, de las Cortes Generales, no existe una relación propiamente de mandato o comisión, sino el ejercicio de una función estatal sostenida por el Parlamento, pero no instrumentalizada por el mismo. De una opinión parecida son Anguita y Carballo $^{6}$, quien considera a su vez acertada la postura de Varela Suanzes-Carpegna al observar que esa relación de órgano auxiliar no se da en términos de paridad, pero tampoco en términos de subordinación o jerarquía. El propio Carballo incide aún más en la autonomía del Defensor del

2 GARRIDO FALLA, Comentarios a la Constitución, GARRIDO FALLA y otros, Civitas, Madrid, 2001, pág. 991.

3 ÁLVAREZ CONDE, Curso de Derecho Constitucional, Volumen I. Editorial Tecnos, Madrid, 2003, pág. 549.

4 SÁINZ MORENO, "Defensor del Pueblo y Parlamento (Relaciones con las Cámaras)", en Diez años de la Ley Orgánica del Defensor del Pueblo. Problemas y Perspectivas. Universidad Carlos III de Madrid. Cátedra Joaquín Ruiz-Giménez de estudios sobre el Defensor del Pueblo, Madrid, 1992, págs. 41 y ss.

5 ANGUITA SUSI, "Algunas notas en torno a la presentación parlamentaria del Informe Anual por los Defensores del Pueblo", en Revista de Derecho Politico, n. ${ }^{\circ}$ 63, 2005, pág. 207

6 CARBAllo ARMAS, El Defensor del Pueblo. El Ombudsman en España y en el Derecho Comparado, Tecnos, Madrid, 2003, págs. 138 y ss. 
Pueblo, manifestada en determinadas características del mismo, como su inviolabilidad, inmunidad, inelegibilidad, fuero especial, y la duración de su mandato, todo lo cual va dirigido a evitar que el Defensor del Pueblo sea un instrumento de la mayoría parlamentaria que lo eligió. Una opinión distinta mantiene Carro, que afirma que estamos ante una especie de relación de fiducia que, en todo caso "no me parece que sea esencialmente distinta de la que existe entre el Gobierno y el Congreso de los Diputados, salvando, lógicamente, la función reservada a cada órgano constitucional ${ }^{7}$.

En nuestra opinión, es muy acertada la caracterización que hace Astarloa Villena ${ }^{8}$ que, tras realizar un análisis del modo de designación, cese, régimen de incompatibilidades y prerrogativas, y duración del mandato, llega a la conclusión de que la relación entre el Defensor del Pueblo y las Cortes Generales se resume en los siguientes términos: dependencia orgánica e independencia funcional. En el mismo sentido se manifiesta Bar Cendón', que termina por concluir que nos encontramos ante una institución híbrida o mixta, ya que a su dependencia de origen y de función de las Cortes Generales, une su independencia de actuación. Sería por tanto una figura sui generis que se integra en la dinámica de la separación y mutuo control de poderes del Estado. Gil-Robles y Gil-Delgado ${ }^{10}$, por su parte, habla de una "total independencia operativa del Defensor del Pueblo".

No es nuestra intención terciar en estas discusiones ya que no es el objeto de este trabajo y debido a que, además, a pesar de las diferencias entre los distintos autores, es cierto que todos coinciden en señalar dos características centrales de la institución del Defensor del Pueblo: por un lado, la autonomía e, incluso, para algunos autores, plena independencia funcional del Defensor del Pueblo, reconocida explícitamente en el artículo 1.2 del Reglamento de Organización y Funcionamiento del Defensor del Pueblo ${ }^{11}$; y, por otro, su configuración como "magistratura de persuasión". Ambas características tienen la finalidad fundamental de que, fuera de consideraciones más pro-

7 CARRO ("Defensor del Pueblo y Administración", Homenaje García de Enterría, 1991, pág. 2674), citado por SÁINZ MORENO, op. cit., pág. 43. LA PERGOLA (op. cit., pág. 80) utiliza también la expresión "relación fiduciaria", pero matiza dicha expresión hasta situarse en una posición muy similar a la mayoritaria al afirmar que la relación fiduciaria no puede ser configurada como una plena subordinación del Defensor del Pueblo a las Cámaras, sino que se le dota al Defensor del Pueblo de una autonomía necesaria para que su objetividad e imparcialidad no se vean comprometidas.

8 ASTARLOA VILLENA, "Veinticinco años de Defensor del Pueblo: una aproximación al origen, naturaleza y estatuto de la institución", en Cuadernos Constitucionales de la Cátedra Fadrique Furió Ceriol, Valencia, 2007, págs. 143 y ss.

9 BAR CENDÓN, "El Defensor del Pueblo en el ordenamiento jurídico español", en El desarrollo de la Constitución española de 1978, Facultad de Derecho de la Universidad de Zaragoza, Libros Pórtico, Zaragoza, 1982, págs. 319 y ss.

10 GIL-ROBLES Y GIL-DELGADO, El control parlamentario de la Administración (El Ombudsman), Instituto Nacional de la Administración Pública, Madrid, 1981, pág. 311.

11 Este precepto establece que el Defensor del Pueblo no estará sujeto a mandato imperativo alguno. No recibirá instrucciones de ninguna autoridad y desempeñará sus funciones con autonomía y según su criterio. 
fundas, el Defensor del Pueblo actúe de un modo independiente desde un punto de vista político, aun cuando han sido las fuerzas políticas quienes lo han elegido. En nuestra opinión, ésta era la intención fundamental del legislador.

Para situar la cuestión, antes de entrar a analizar los distintos aspectos al detalle, relacionamos a continuación la normativa aplicable a esta materia:

- Ley Orgánica 3/1981, de 6 de abril, del Defensor del Pueblo (en adelante, LODP) modificada por la Ley Orgánica 2/1992, de 5 de marzo, a efectos de constituir una Comisión Mixta Congreso de los Diputados-Senado de Relaciones con el Defensor del Pueblo. Reglamento de Organización y Funcionamiento del Defensor del Pueblo (en adelante ROFDP), aprobado por Acuerdo de las Mesas del Congreso y del Senado, en su reunión conjunta de 6 de abril de 1983. Resolución de las Mesas del Congreso de los Diputados y del Senado de 21 de abril de 1992, sobre organización y funcionamiento de la Comisión Mixta de Relaciones con el Defensor del Pueblo. Esta Resolución crea la citada Comisión Mixta, que sustituye a las Comisiones que anteriormente existían en cada una de las dos Cámaras. En esta norma se establece que la Comisión estará formada por los miembros designados por los Grupos Parlamentarios en el número que, respecto de cada uno, acuerden las Mesas del Congreso de los Diputados y del Senado, en reunión conjunta, para cada Legislatura $^{12}$. Esta Resolución fue objeto de una importante reforma a través de otra Resolución de ambas Mesas de 25 de mayo de 2000, a través de la cual se introdujo el trámite de comparecencias previas de los candidatos a Defensor del Pueblo, que más tarde analizaremos. A esta Comisión se le atribuye el ejercicio de las funciones previstas en la LODP y en el ROFDP así como el conocimiento de los asuntos que le encomienden las Mesas del Congreso de los Diputados y el Senado. Esta previsión coincide con lo establecido en el artículo 2.2 de la LODP, según el cual se designará en las Cortes Generales una Comisión Mixta Congreso de los Diputados-Senado encargada de relacionarse con el Defensor del Pueblo e informar a los respectivos Plenos en

12 En la IX Legislatura la Comisión Mixta de Relaciones con el Defensor del Pueblo, de acuerdo con la Resolución de las Mesas del Congreso de los Diputados y del Senado sobre composición de las Comisiones Mixtas Congreso-Senado, de 26 de mayo de 2008, está compuesta por cuarenta y tres miembros, más cuatro adscritos. Los Grupos Parlamentarios ostentan una representación proporcional a su número de miembros en los Plenos de ambas Cámaras: 19 del Grupo Socialista (12 Diputados y 7 Senadores), 19 del Grupo Popular (10 Diputados y 9 Senadores), 1 del Grupo Catalán (1 Diputado o 1 Senador, en este caso se trata de una Diputada), 1 del Grupo Vasco (1 Diputado o 1 Senador, en este caso se trata de un Diputado), 1 del Grupo Entesa (1 Senador), 1 del Grupo ERC-IU-ICV (1 Diputado) y 1 del Grupo Mixto (1 Diputado o 1 Senador, en este caso se trata una Diputada). En lo que se refiere a la división entre Diputados y Senadores, siguiendo también un criterio proporcional, hay 26 Diputados y 17 Senadores. La Resolución citada anteriormente señala que la sede de las Comisiones Mixtas se encontrará en la Cámara a la que pertenezca su Presidencia. Como en la presente Legislatura la Presidencia de la Comisión Mixta de Relaciones con el Defensor del Pueblo corresponde a una Diputada, la sede de la Comisión se encuentra en el Congreso de los Diputados. 
cuantas ocasiones sea necesario. Resolución de la Presidencia del Congreso de los Diputados sobre tramitación ante el Pleno de los Informes Anuales o Extraordinarios del Defensor del Pueblo, de 21 de abril de 1992. Resolución de la Presidencia del Senado, sobre tramitación ante el Pleno de la Cámara de los Informes del Defensor del Pueblo, de 28 de abril de 1992.

A través de este conjunto de normas se da respuesta a los distintos aspectos que configuran la relación entre el Defensor del Pueblo y las Cortes Generales. Pasamos ya a estudiar estas cuestiones.

\section{NOMBRAMIENTO Y CESE DEL DEFENSOR DEL PUEBLO}

El sistema de elección del Defensor del Pueblo se encuentra recogido en el artículo 2 de la LODP, según el cual el Defensor del Pueblo será elegido por las Cortes Generales por un período de cinco años. El apartado 2.1 de este artículo, redactado según la L.O. 2/1992, establece, siguiendo el mandato constitucional, que el Defensor del Pueblo será designado por las Cortes Generales por un período de cinco años. Se establece, por tanto, un mandato de superior duración al de las propias Cortes Generales, lo cual se ha interpretado como un medio de reforzar la autonomía e independencia del Defensor del Pueblo.

El apartado 3 del artículo 2 de la LODP señala que la Comisión Mixta se reunirá para proponer uno o varios candidatos a los Plenos de las Cámaras por mayoría simple. A continuación, el apartado cuatro establece que propuesto el candidato o candidatos, se convocará en término no inferior a diez días al Pleno del Congreso para que proceda a su elección. Será designado quien obtuviese una votación favorable de las tres quintas partes de los miembros del Congreso y, posteriormente, en un plazo máximo de veinte días, fuese ratificado por esta misma mayoría del Senado. En el caso de que no se obtuvieran estas mayorías, la Comisión Mixta, según el apartado 5 del artículo 2, tendrá que formular nuevas propuestas en el plazo de un mes, de tal forma que obtendrá la designación el candidato que obtenga mayoría de tres quintos en el Congreso de los Diputados y mayoría absoluta en el Senado. Observamos que la LODP exige la mayoría cualificada establecida en la Constitución y su normativa de desarrollo para la elección de los miembros de los órganos constitucionales y de relevancia constitucional (entre estos últimos se incluye al Defensor del Pueblo junto con el Tribunal de Cuentas ${ }^{13}$ ).

13 La caracterización del Defensor del Pueblo como órgano de relevancia constitucional es, como señala CARBALLO (op. cit., págs.140 y ss.), mayoritaria en la doctrina, aunque existen opiniones contrarias, como las de ASTARLOA VILLENA o RUIZ-GIMÉNEZ (citados por CARBALLO), que consideran que el Defensor del Pueblo entra dentro de la categoría órgano constitucional. En la posición mayoritaria que configura al Defensor el Pueblo como órgano de relevancia constitucional se encuentran, entre otros, AGUILAR FERNÁNDEZ-HONTORIA o GARCÍA-PELAYO $\mathrm{y}$, dentro de la doctrina italiana, CHELI. 
En la Resolución de 21 de abril de 1992 sobre funcionamiento de la Comisión Mixta se establece la posibilidad de que la Mesa de la Comisión, a iniciativa propia o de un Grupo Parlamentario, acuerde la comparecencia de alguno de los candidatos propuestos. En dicha comparecencia los Grupos Parlamentarios podrán preguntar al candidato cualquier extremo relacionado con su trayectoria profesional o personal ${ }^{14}$. Vemos por tanto que desde un primer momento el Defensor del Pueblo está claramente vinculado a las Cortes Generales, ya que tendrá que comparecer allí incluso antes de ser Defensor del Pueblo, y más desde el momento en el que se establece la necesidad de comparecer para poder ser designado, ya que si un candidato no comparece en la Comisión en este trámite, quedará excluido del proceso de designación.

En lo que se refiere al cese, el artículo 5 de la LODP señala que las causas de cese son la renuncia, la expiración del plazo, la muerte o incapacidad sobrevenida, haber desempeñado su cargo con notoria negligencia o haber sido condenado mediante sentencia firme por delito doloso. Aquí también intervendrán las Cortes Generales o su Presidente, ya que según el artículo 5.2 la vacante en el cargo se declarará por el Presidente del Congreso en los casos de muerte, renuncia y expiración del plazo del mandato. En los demás casos se decidirá por mayoría de las tres quintas partes de los componentes de cada Cámara, mediante debate y previa audiencia del interesado ${ }^{15}$.

Esta regulación del cese del Defensor puede causar en ocasiones perplejidad y en otras cierta confusión ${ }^{16}$. Por un lado, no se entiende muy bien por qué las Cámaras tienen que pronunciarse con una mayoría de tres quintos a favor del cese del Defensor del Pueblo en los casos de incapacidad sobrevenida y de condena firme por un delito doloso. En el supuesto de la incapacidad sobrevenida, sería absurdo mantener a un Defensor del Pueblo incapacitado civilmente; además, esto sería ilegal, ya que el artículo 3 de la

14 SÁINZ MORENO (op. cit., pág. 50) consideraba, antes de la reforma por la que se introdujo este trámite de comparecencias previas, que dicho trámite si bien podía aumentar la transparencia del procedimiento de designación, podía suponer también una vía para ejercer presión sobre las Cámaras por entidades ajenas al Parlamento.

15 En el momento en el que se escribe este trabajo, el cargo de Defensor del Pueblo se encuentra vacante por expiración del mandato; esta vacante fue declarada el 30 de junio de 2010 por el Presidente del Congreso al haber terminado el mandato del anterior Defensor del Pueblo, Excmo. Sr. D. Enrique Múgica Herzog. Ahora, por tanto, son las Cortes Generales las que tienen que dar el siguiente paso, ya que el artículo 5.3 de la LODP señala que en un plazo no superior a un mes desde el cese se debe iniciar el procedimiento para designar al nuevo Defensor del Pueblo. Actualmente, está ejerciendo de manera interina el cargo la Adjunta Primera, D. ${ }^{a}$ María Luisa Cava de Llano. Poco antes de su cese, el 22 de junio de 2010, el Sr. Múgica hizo entrega al Presidente del Congreso del Informe Anual correspondiente al año 2009. El 19 de julio de 2010, la Mesa del Congreso de los Diputados acordó admitir a trámite el Informe Anual, trasladarlo a la Comisión Mixta de Relaciones con el Defensor del Pueblo, poner esta circunstancia en conocimiento del Senado y ordenar la publicación del Informe en el Boletín Oficial de las Cortes Generales, publicación que tuvo lugar el 22 de julio de 2010. En el día en el que este trabajo se termina, aún no se ha convocado la Comisión Mixta para que comience la tramitación parlamentaria del Informe.

16 Cfrs. ASTARLOA VILLENA (op. cit, págs. 149 y 150) y CARBALLO (op. cit., págs. 174 y ss.) 
LODP establece que para poder ser elegido Defensor del Pueblo hay que estar en pleno uso de los derechos civiles y políticos. En lo que respecta al supuesto de condena firme por delito doloso, resultaría ridículo que las Cortes Generales mantuviesen en el cargo a un Defensor del Pueblo condenado por el Poder Judicial. Se crearía un conflicto gravísimo entre Poderes, ya que las Cortes Generales no deben revisar el pronunciamiento de la Justicia y, menos aún, mantener como Defensor del Pueblo a un delincuente. En consecuencia, en estos dos supuestos, lo conveniente sería reformar la LODP para que el cese en estos casos fuese automático.

Cuestión distinta es la que se refiere al cese por notoria negligencia en el cumplimiento de los deberes y obligaciones del cargo. Aquí sí que es necesaria una intervención de las Cortes Generales, ya que, del mismo modo que en su momento le otorgaron la confianza al Defensor del Pueblo pueden retirársela cuando lo consideren oportuno. No en vano el Defensor del Pueblo es el Alto Comisionado de las Cortes Generales, por lo que puede perder la confianza que obtuvo de éstas. Aquí se ha seguido, más o menos, el sistema sueco, en el que se prevé que el Parlamento puede sustituir al Ombudsman cuando éste ha perdido su confianza. En nuestra opinión, es en este sentido como hay que entender esta previsión, es decir, como señala Gil-Robles y GilDelgado $^{17}$, esta vía es el camino para "derribar por razones políticas al Defensor del Pueblo". Pueden también incluirse otros supuestos bastante inverosímiles, como que el Defensor del Pueblo no contestase a ninguna de las quejas, no presentase los Informes, no compareciera nunca ante las Cámaras o, en general, ejerciese su cargo con absoluta dejadez. Si esto sucediese, ésta sería la vía para lograr el cese del Defensor del Pueblo. Sin embargo, parece que la intención de esta previsión era establecer un sistema de cese en el caso de que las Cortes Generales hubiesen perdido la confianza política en el Defensor del Pueblo ${ }^{18}$. Si se produjese esta situación, sería la Comisión Mixta la que debería instar el procedimiento para que se procediese al cese del Defensor del Pueblo.

Esta dependencia en el nombramiento y en el cese de las Cortes Generales también afecta a sus Adjuntos que, aunque propuestos por el Defensor del Pueblo (según el artículo 8b) del ROFDP), requieren para su nombramiento la conformidad de la Comisión Mixta. La propia Comisión tendrá también, de acuerdo con la Resolución que regula su funcionamiento, la posibilidad de solicitar la evacuación del trámite de comparecencias previas para su nombramiento. En cuanto a su cese, los Adjuntos cesarán automáticamente en el mo-

17 Op. cit., pág. 249.

18 Algunos políticos, e incluso algunos Grupos Parlamentarios, han mostrado durante el mandato del Sr. Múgica su descontento con alguna de sus actuaciones como, por ejemplo, haber interpuesto recurso de inconstitucionalidad contra el Estatuto de Autonomía de Cataluña o, más recientemente, por haber insultado a quienes no comparten su afición por los toros. A partir de ahí, se alzaron algunas voces pidiendo el cese del Sr. Múgica por considerar que no estaba ejerciendo su cargo adecuadamente. 
mento de la toma de posesión del nuevo Defensor del Pueblo, ejerciendo el Adjunto Primero interinamente las funciones de Defensor del Pueblo cesante hasta la designación por las Cortes Generales del nuevo titular.

Para terminar con este punto, podemos señalar cómo Sáinz Moreno ${ }^{19}$ se manifestaba claramente en contra del sistema de cese elegido por la LODP, ya que, según su opinión, "no se comprende por qué ha de producirse el cese automático del titular de la institución que ha sido elegido por los Plenos de las Cámaras y, en cambio, mantener la de un Adjunto cuya legitimación es menor ya que ha sido elegido por el propio Defensor, aunque baya recibido la conformidad de la Comisión Mixta». Por tanto, para Sáinz Moreno sería más eficaz que el Defensor del Pueblo cesante continúe ejerciendo sus funciones hasta que sea designado el nuevo titular del cargo.

\section{LA PRESENTACIÓN DE LOS INFORMES DEL DEFENSOR DEL PUEBLO.}

La labor fundamental del Defensor del Pueblo como supervisor de la actividad de la Administración Pública para defender los derechos de los ciudadanos, se manifiesta a través de la tramitación de las quejas de éstos y de su correspondiente investigación, de su legitimación para interponer recursos de inconstitucionalidad y de amparo y de la posibilidad de formular a las autoridades y funcionarios recordatorios, recomendaciones o sugerencias. Incluso, el Defensor del Pueblo tiene la posibilidad de poner en conocimiento del Ministerio Fiscal los casos en los que aprecie indicios de delito.

Del ejercicio de esta capital función, el Defensor del Pueblo debe dar cuenta a las Cortes Generales por mandato constitucional. En opinión de Anguita $^{20}$, dentro de los rasgos esenciales que definen la idiosincrasia del Defensor del Pueblo, destaca la necesidad de trasladar al Parlamento el resultado de la actividad desplegada. La correcta realización de este trámite permitirá, como señala este autor, que el Defensor del Pueblo cumpla con la misión de supervisión que tiene encomendada, así como que el Parlamento cuente con el material necesario para adoptar las medidas que ayuden a combatir los problemas señalados en los Informes. Para Bar Cendón ${ }^{21}$ la presentación de estos Informes constituye "la parte de mayor trascendencia de su actividad, por la publicidad que adquiere y por el carácter de la instancia a la que se dirige». La Pergola ${ }^{22}$ afirmó que el "Ombudsman está obligado, sin excepción, a exponer a las Cámaras periódicamente su actividad".

Por ello, el artículo 32 de la LODP obliga al Defensor del Pueblo a presentar un Informe Anual a las Cortes Generales cuando se hallen reunidas en

19 Op. cit., págs. 56 y 57.

20 Op. cit., pág. 206.

21 Op. cit., pág. 355

22 Op. cit., pág. 80. 
período ordinario de sesiones; además, el Defensor del Pueblo podrá presentar Informes Extraordinarios por razones de urgencia. Estos Informes serán publicados en la forma que más tarde veremos. En el Informe Anual, según el artículo 33 de la LODP, se harán constar el número y tipo de quejas presentadas, aquéllas que hubiesen sido rechazadas y sus causas, así como las que fueron objeto de investigación y el resultado de la misma, con especificación de las sugerencias o recomendaciones admitidas por las Administraciones Públicas. Además, deberá incluir este Informe un anexo cuyo destinatario serán las Cortes Generales, en el que se hará constar la liquidación del presupuesto de la institución en el período que corresponda. En ningún caso constarán los datos personales que permitan la pública identificación de los interesados en el procedimiento de investigación, sin perjuicio de lo establecido en el artículo 24.1 de la LODP23.

En relación con el momento en el que debe presentarse el Informe, la LODP no ha establecido uno concreto. Para Anguita ${ }^{24}$ esto debería modificarse y fijar una fecha o al menos un período de referencia (como se hace en la Ley del Sindic de Greuges, en la Ley del Justicia Aragonés o en la Ley canaria) en el que el Defensor del Pueblo debiese presentar el Informe, ya que, según este autor, la presentación extemporánea impediría realizar correctamente la dación de cuentas. Además, la fijación de la fecha sería una garantía para el Defensor del Pueblo, ya que le permitiría evitar eventuales intereses políticos dirigidos a que la presentación del Informe se adelante o se demore.

En lo que se refiere a la tramitación parlamentaria de los Informes, la LODP simplemente establece en el artículo 33.4 que el Defensor del Pueblo expondrá oralmente ante los Plenos de ambas Cámaras un resumen de los mismos, pudiendo intervenir los Grupos Parlamentarios a efectos de fijar su posición. Esta previsión ha sido desarrollada por la Resolución por la que se regula el funcionamiento de la Comisión Mixta, según la cual, antes de que el Defensor del Pueblo presente sus Informes ante el Pleno, éstos serán sometidos a examen de la Comisión, a través de un procedimiento en el que en primer lugar el Defensor del Pueblo expondrá el Informe sin límite de tiempo; a continuación intervendrán los Grupos Parlamentarios por un tiempo máximo de diez minutos para formular preguntas o pedir aclaraciones y, finalmente, contestará el Defensor del Pueblo. El Presidente de la Comisión, de acuerdo con la Mesa y oídos los Portavoces, podrá abrir un turno breve de réplica.

Respecto a la tramitación de los Informes ante los Plenos, en el Congreso de los Diputados, el artículo 200 de su Reglamento establece que recibido el Informe Anual o un Informe Extraordinario del Defensor del Pueblo y, una vez que haya sido incluido en el orden del día, aquél expondrá oralmente

23 Dicho artículo establece que la persistencia de una actitud hostil o entorpecedora de la labor de investigación del Defensor del Pueblo por parte de cualquier organismo, funcionarios, directivo o persona al servicio de la Administración pública podrá ser objeto de un informe especial, además de destacarlo en la sección correspondiente de su Informe Anual.

24 Op. cit., pág. 209. 
ante el Pleno o, en su caso, ante la Diputación Permanente, un resumen del mismo. Tras esta exposición, podrá hacer uso de la palabra por tiempo máximo de quince minutos un representante de cada Grupo Parlamentario para fijar su posición. La Resolución de 21 de abril de 1992 sobre la tramitación de los Informes ante el Pleno del Congreso de los Diputados añade a esto que las deliberaciones comenzarán tras la ausencia del Defensor del Pueblo ${ }^{25}$ y que tras la intervención de los Grupos Parlamentarios no podrán presentarse propuestas de resolución, sin perjuicio de las iniciativas reglamentarias que puedan proponerse. Este último inciso se refiere a la posibilidad de que algún Diputado o Grupo Parlamentario, como consecuencia de la presentación realizada por el Defensor del Pueblo, decida presentar alguna pregunta, interpelación o proposición no de ley, las cuales, lógicamente, irán dirigidas al Gobierno. Además, como señala Carballo ${ }^{26}$, podría solicitarse la presencia de los miembros del Gobierno a través del mecanismo previsto en el artículo 110 de la Constitución o, incluso, la posibilidad de solicitar que se cree una Comisión de Investigación ${ }^{27}$.

Álvarez Conde ${ }^{28}$ afirma que es dudoso que a través de la presentación del Informe que lleva a cabo el Defensor del Pueblo, se pueda llevar a cabo un control político del Defensor, aunque, según este autor, nada parece impedir un pronunciamiento contrario de las Cámaras, o de una de ellas, ante la gestión realizada por éste. En nuestra opinión, esta afirmación no es correcta si nos atenemos a la regulación que establece la normativa de desarrollo de los

25 Esto es lo que se deduce de la muy deficiente redacción de la Resolución en este punto, ya que la redacción textual es "Exposición del Defensor del Pueblo de un resumen del Informe, tras cuya ausencia comenzarán las deliberaciones", y es que con esta redacción parece que quien tendrá que ausentarse será el Informe, cosa que, aparte de metafísicamente imposible, no parece muy útil.

26 Op. cit., pág. 229.

27 CARBALLO muestra su preocupación sobre el hecho de que al ir estas actividades de control, como hemos señalado, dirigidas al Gobierno de la Nación, las Cortes Generales verían muy limitadas sus capacidades de control ante las actuaciones de las Administraciones de las Comunidades Autónomas. Esto lleva a este autor a concluir que "El Defensor del Pueblo puede supervisar la actuación de todas las Administraciones Públicas... Sin embargo, esta actividad sólo puede ser continuada parcialmente por las Cortes Generales" (op. cit., págs. 231 y 232). Este autor considera que las soluciones a este problema, además de la existencia de los Defensores Autonómicos, son que el Ejecutivo tome buena nota de las consideraciones del Defensor del Pueblo estatal sobre la actividad de las Administraciones Públicas autonómicas y ejercitar todas las medidas de control que estén a su alcance. En nuestra opinión, la gravedad del problema disminuye con la actual configuración del Estado autonómico, extraordinariamente descentralizado, en el que las Comunidades Autonómicas cuentan con una configuración de sus Administraciones que, además de estar totalmente asimiladas a la del Estado, ejercen importantísimas competencias que afectan a aspectos centrales de la vida de los ciudadanos; de ahí que la realidad sea que la actividad de supervisión realizada por el Defensor Autonómico deba ser continuada por la correspondiente Asamblea Legislativa autonómica. En definitiva, parece que esa parte de la supervisión de la actividad de la Administración autonómica del Defensor del Pueblo estatal que las Cortes Generales no pueden continuar, puede ser cubierta por los Defensores autonómicos y por las Asambleas Legislativas.

28 Op. cit., pág. 550. 
Reglamentos de ambas Cámaras. Como hemos visto, esta regulación impide que, una vez realizado el debate consiguiente a la presentación del Informe por el Defensor del Pueblo, se presenten propuestas de resolución, que son la forma en la que las Cámaras, como tales, pueden emitir un determinado pronunciamiento. Ni los Plenos de las Cámaras ni la Comisión someten a votación ni hacen suyo o rechazan los Informes del Defensor del Pueblo, ni emiten dictamen alguno. Por tanto, la única forma de que las Cámaras, o una de ellas, pudiese realizar un pronunciamiento en contra de un Informe del Defensor del Pueblo o de su gestión, sería que se presentase una proposición no de ley o una moción en Pleno o en la Comisión Mixta con el fin de censurar el contenido del Informe, la gestión del Defensor del Pueblo o alguna actuación concreta de éste. La utilización de una proposición no de ley o de una moción con tal fin se antoja bastante remota, ya que de la regulación de desarrollo de los Reglamentos se deduce la intención del legislador parlamentario de evitar precisamente que el Poder Legislativo como tal pueda criticar la labor del Defensor del Pueblo, ya que esto, como señala Sáinz Moreno ${ }^{29}$, menoscabaría claramente su autonomía y podría interpretarse como un ejercicio de presión contra el Defensor del Pueblo. En todo caso, si se presentase una proposición no de ley o una moción con ese fin, y fuese calificada, sería una iniciativa independiente al trámite parlamentario de los Informes del Defensor del Pueblo, que además podría tardar bastante en tiempo en ser incluida en un orden del día, por lo que perdería actualidad. Aun así, insistimos, esta opción no es nada plausible. Otra cosa es que algún político, o algún Grupo parlamentario, en el uso de su legítimo derecho de libertad de expresión, critique o valore la gestión del Defensor del Pueblo, como puede criticar o valorar la de cualquier otro órgano del Estado o que, desde luego y como ya hemos señalado, utilice alguno de los mecanismos de control para requerir al Gobierno información sobre un determinado aspecto señalado por el Defensor del Pueblo. Si se considera que el Defensor del Pueblo ha realizado alguna actuación con la que no se está de acuerdo, se podrá solicitar su comparecencia ante la Comisión Mixta para que dé explicaciones. Incluso, si se considera que determinadas actuaciones o declaraciones son inaceptables o negligentes se podría intentar instar el cese del Defensor del Pueblo ${ }^{30}$.

Lo que la regulación reglamentaria no permite es, en conclusión, presentar propuestas de resolución en las que las Cámaras, de manera subsiguiente a la presentación de los Informes, expresen su opinión concretamente

29 Op. cit., pág. 62

30 Recordamos aquí los ejemplos citados anteriormente a pie de página cuando hablábamos del cese del Defensor del Pueblo por notoria negligencia en el ejercicio de su cargo. En el caso de los insultos a los no aficionados a los toros, actualmente está calificada una iniciativa del Grupo Catalán-CiU en el Senado para que el Defensor del Pueblo explique las razones por las que profirió esos insultos. Esa comparecencia ya no podrá tener lugar ya que el Sr. Múgica ha cesado en el cargo pero, en el caso de que se hubiera sustanciado, la comparecencia habría consistido en un intercambio de opiniones entre el Defensor del Pueblo y los Grupos Parlamentarios, sin ningún tipo de votación posterior. 
sobre el Informe del Defensor del Pueblo o sobre la gestión de éste. Todo esto se entiende sin perjuicio de la capacidad de las Cortes Generales de vigilar que el Defensor del Pueblo no ejerza su cargo con notoria negligencia así como de que se realice alguna de las actuaciones señaladas en el párrafo anterior. Este sistema, aunque puede parecer complejo, va dirigido a salvaguardar la ya citada independencia del Defensor del Pueblo, que, como hemos dicho, podría verse seriamente dañada si las Cámaras como tal se pronunciasen en contra de su gestión o de alguna de sus actuaciones concretas.

La tramitación de los Informes en el Senado es muy similar, si bien su Reglamento es más escueto, ya que su artículo 183 señala que los Informes que por imperativo legal deban someterse al Senado serán objeto de deliberación y tramitación en la forma que establezca el Presidente, de acuerdo con la Mesa, oída la Junta de Portavoces. La Resolución de la Presidencia del Senado de 28 de abril de 1992 por la que se establece la tramitación de los Informes ante el Pleno del Senado establece una regulación idéntica a la fijada para el Congreso de los Diputados, incluyendo la exclusión de la posibilidad de presentar propuestas de resolución tras el debate.

Esta regulación de la tramitación parlamentaria de los Informes ha recibido alguna crítica por parte de la doctrina. Así Sánchez-Saudinós y Pajares ${ }^{31}$ no entienden por qué mientras en la Comisión Mixta se pueden hacer preguntas al Defensor del Pueblo, en el Pleno el Defensor del Pueblo se ausenta al terminar de realizar su presentación sin que los parlamentarios le puedan hacer preguntas, o por qué se tiene que presentar hasta tres veces el Informe (una en la Comisión Mixta y una vez ante cada Pleno). En relación con la primera pregunta, creemos que la argumentación de estos autores es correcta, ya que se puede decir que quién mejor que el Defensor del Pueblo, como Alto Comisionado de las Cortes Generales, para comparecer ante el Pleno de las Cámaras y responder preguntas de los parlamentarios. Pero la realidad es que el legislador parlamentario, por las razones que sean, no lo ha querido así, como tampoco lo ha querido de ninguna otra Autoridad del Estado o ciudadano que no sea miembro del Gobierno. Respecto de la segunda pregunta, estos autores proponen que los Informes del Defensor del Pueblo se presenten únicamente ante la Comisión Mixta, y es que entienden que así se simplificaría el trámite y que no se reduciría el impacto en la opinión pública de la presentación de los Informes del Defensor del Pueblo por el hecho de que no se exponga ante los Plenos. No podemos estar de acuerdo con esta afirmación. Para empezar, las sesiones de las Comisiones no son públicas, lo cual ya reduce inmensamente la difusión del contenido de la sesión, por mucho que puedan entrar medíos de comunicación acreditados. Por otro lado, el Pleno es el órgano decisor de la Cámara, aquél en el que está plenamente manifestada la voluntad parlamentaria; por ello, allí debe comparecer el Defensor del Pueblo en principio para cumplir con su obligación de rendir cuentas.

31 SÁNCHEZ SAUDINÓS y PAJARES, "Comentario al artículo 33", en Comentarios a la Ley Orgánica del Defensor del Pueblo, dirigidos por ROVIRA, Aranzadi, Madrid, 2002, págs. 839 y ss. 
Cierto es que el Derecho Parlamentario es flexible y que de la misma manera que decidieron que el Defensor del Pueblo se ausentase después de presentar el Informe en el Pleno, las Cámaras podrían haber decidido a través de las normas de desarrollo de sus Reglamentos delegar la comparecencia del Defensor del Pueblo únicamente en la Comisión Mixta. De momento no lo ha hecho, en nuestra opinión, para preservar el impacto mediático de la presentación del Informe del Defensor del Pueblo y porque, además, habría que reformar el artículo 33.4 de la LODP y el artículo 200 del Reglamento del Congreso de los Diputados, que exigen que la presentación de los Informes se realice ante los Plenos de las Cámaras.

No hay que olvidar una mención establecida en el artículo 200.2 del Reglamento del Congreso de los Diputados, según el cual los Diputados, los Grupos Parlamentarios y las Comisiones podrán solicitar, mediante escrito motivado y a través del Presidente del Congreso, la intervención del Defensor del Pueblo para la investigación o esclarecimiento de actos, resoluciones y conductas concretas producidas en las Administraciones Públicas, que afecten a un ciudadano o grupo de ciudadanos. Esta previsión no se encuentra recogida en el Reglamento del Senado, lo cual no excluye que los Senadores, Grupos Parlamentarios y Comisiones del Senado puedan ejercer estas actividades, ya que la previsión del Reglamento del Congreso de los Diputados proviene del artículo 10.2 de la LODP, que también otorga estas facultades a los Senadores. En todo caso, y como señala el artículo 10.2, será la Comisión Mixta la que deberá ejercer "principalmente" estas funciones. Esta previsión se complementa con lo establecido en el artículo 11.2 del ROFDP, según el cual el Defensor del Pueblo podrá dar cuenta periódicamente a la Comisión Mixta de sus actividades con relación a un período determinado o a un tema concreto, y la Comisión Mixta podrá recabar del mismo cualquier información.

Por último, y en relación con el mandato señalado en el artículo 32.3 sobre la publicación de los Informes del Defensor del Pueblo, la Resolución por la que se regula el funcionamiento de la Comisión Mixta establece que en la Seria A, "Actividades parlamentarias" del Boletín Oficial de las Cortes Generales se publicarán el Informe Anual o los Informes Extraordinarios del Defensor del Pueblo que hayan de tramitarse en la Comisión Mixta de Relaciones con el Defensor del Pueblo. Además, hay que señalar que la Dirección de Estudios de la Secretaría General del Congreso de los Diputados publica el Informe Anual del Defensor del Pueblo, junto con los debates parlamentarios que derivan de la presentación del mismo.

\section{LOS MEDIOS PERSONALES, MATERIALES Y ECONÓMICOS DEL DEFENSOR DEL PUEBLO. OTROS ASPECTOS DE SUS RELACIONES CON LAS CORTES GENERALES}

Los artículos 34 a 36 de la LODP establecen el régimen general del personal al servicio del Defensor del Pueblo, que tiene las dos siguientes carac- 
terísticas fundamentales: —El Defensor del Pueblo podrá designar libremente los asesores necesarios para el ejercicio de sus funciones, de acuerdo con el Reglamento y dentro de los límites presupuestarios-. Las personas que se encuentren al servicio del Defensor del Pueblo, y mientras permanezcan en el mismo, se considerarán como personal al servicio de las Cortes.

El ROFDP añade a esta regulación que el personal al servicio del Defensor del Pueblo es personal de las Cortes Generales sin perjuicio de la dependencia orgánica y funcional del Defensor del Pueblo. Además, aclara el sistema de designación, ya que según el artículo 27 la selección del personal al servicio del Defensor del Pueblo se realizará por éste libremente, con arreglo a los principios de mérito y capacidad. En estos nombramientos se procurará dar prioridad a funcionarios públicos. El resto del personal que no reúna las condiciones de funcionario de carrera de las Administraciones Públicas tendrá el carácter de funcionario eventual al servicio del Defensor del Pueblo.

En consecuencia, el Defensor del Pueblo tiene una autonomía prácticamente absoluta para configurar el personal que tendrá a su servicio, y no tendrá que dar cuenta a las Cortes Generales más allá de lo que se ha señalado anteriormente sobre le nombramiento de los Adjuntos.

Esta regulación del personal al servicio del Defensor del Pueblo resulta algo confusa, y aún más que no se haya modificado cuando voces autorizadas como Sáinz Moreno $^{32}$ llamaron la atención hace ya dieciocho años sobre la necesidad de acometer dicha reforma. Y es que si bien la LODP establece que el personal al servicio del Defensor del Pueblo se considerará personal de las Cortes Generales, tanto el Estatuto del Personal de las Cortes Generales (en adelante, EPCG) como el ROFDP parecen ignorar esta circunstancia.

El EPCG desconoce totalmente que el personal al servicio del Defensor del Pueblo sea considerado como personal de las Cortes Generales; de hecho, esta circunstancia no aparece mencionada en el mismo, que sólo hace referencia a que los funcionarios de las Cortes Generales que pasan a prestar sus servicios en el Defensor del Pueblo entran en situación de servicios especiales (artículo 19 EPCG).

Por su parte, el ROFDP establece, como hemos visto, el sistema de libre designación, y que quienes no tengan carácter de funcionario, serán considerados funcionarios eventuales. La desvinculación del personal del Defensor del Pueblo de las Cortes Generales es tan grande que, como señala Sáinz Moreno, ni siquiera cabe un recurso de alzada ante las Mesas del Congreso de los Diputados y del Senado, ya que los recursos ante el Defensor del Pueblo agotan la vía administrativa.

En definitiva, aunque la LODP afirma taxativamente que el personal del Defensor del Pueblo es personal al servicio de las Cortes Generales, la realidad parece decir lo contrario. No se entiende por qué en la importante reforma del EPCG que tuvo lugar en 2006 no se solucionó esta cuestión, bien

32 Op. cit., págs. 69 y 70. 
para integrar de verdad al personal del Defensor del Pueblo en el de Cortes Generales, bien para acomodar la norma a la realidad y separarlo completamente. En todo caso, si se quiere mantener la situación actual, al menos habría que eliminar la caracterización que la LODP hace del personal del Defensor del Pueblo como personal de Cortes Generales, porque realmente su única vinculación con éstas (y quizá la razón por la que la LODP utilizó la fórmula que utiliza) es que su retribución proviene de su Presupuesto, mientras que el ejercicio de sus funciones y su régimen organizativo y disciplinario no dependen en nada de las Cámaras.

En lo que se refiere a su régimen económico, la LODP establece únicamente en su artículo 37 que la dotación económica necesaria para el funcionamiento de la institución constituirá una partida dentro de los presupuestos de las Cortes Generales. A partir de la previsión general del artículo 8 j), según el cual corresponde al Defensor del Pueblo aprobar, de acuerdo con las directrices generales fijadas por las Mesas del Congreso y del Senado, el proyecto de Presupuesto de la institución y acordar su remisión al Presidente del Congreso, para su aprobación definitiva por las citadas Mesas, e incorporación a los Presupuestos de las Cortes Generales, el ROFDP añade en sus artículos 35 a 38 las siguientes cuestiones:

- El presupuesto de la institución del Defensor del Pueblo se integrará en la sección presupuestaria del Presupuesto de las Cortes Generales como un servicio más del mismo. El régimen de contabilidad e intervención que se aplicará en el Defensor del Pueblo será el de las Cortes Generales. El Interventor de las Cortes Generales ejercerá la función crítica y fiscalizadora de conformidad con la normativa aplicable a las Cortes Generales.

- La estructura del Presupuesto de la institución del Defensor del Pueblo se acomodará a la del Presupuesto de las Cortes Generales. Se aplicarán las normas que rijan en las Cortes Generales para la transferencia de créditos entre conceptos presupuestarios. La autorización de transferencias se realizará por el Defensor del Pueblo, con el informe del Interventor de las Cortes Generales.

- Las competencias en materia de ordenación de pagos corresponderán a la Junta de Coordinación y Régimen Interior, al Defensor del Pueblo y al Secretario General en función de la cuantía y en la forma que determine la citada Junta, a propuesta del Defensor del Pueblo. La ordenación del pago corresponde al Defensor del Pueblo.

- El régimen de contratación y de adquisición en general en el Defensor del Pueblo será el que rija para las Cortes Generales.

A diferencia de lo que sucede con el régimen de personal, en el que se apreciaba una gran autonomía del Defensor del Pueblo para organizar a las personas a su servicio, en el ámbito del régimen económico se aprecia una dependencia férrea de las Cortes Generales sobre todo en lo que se refiere a 
la elaboración, aprobación, ejecución y control del Presupuesto, donde el Interventor de las Cortes Generales tendrá una función fundamental. En este ámbito llama sin embargo la atención, por romper con la relación paralela y en régimen de igualdad que mantiene durante todo su mandato el Defensor del Pueblo con las dos Cámaras, el hecho de que la pensión indemnizatoria a la que tiene derecho el Defensor del Pueblo cuando cesa en su cargo sea concedida no por Acuerdo de ambas Mesas en reunión conjunta, sino por Acuerdo únicamente de la Mesa del Congreso de los Diputados.

Para terminar, podemos dar cuenta de otros tres aspectos en los que se manifiesta la importante relación entre el Defensor del Pueblo y las Cortes Generales:

- En primer lugar, el artículo 11.1 y 2 de la LODP asegura que el Defensor del Pueblo ejercerá sus funciones independientemente de la situación en la que se encuentren las Cámaras. Así, se establece que la actividad del Defensor del Pueblo no se verá interrumpida en los casos en que las Cortes Generales no se encuentren reunidas, hubieren sido disueltas o hubiere expirado su mandato, y que en estas situaciones, el Defensor del Pueblo se dirigirá a las Diputaciones Permanentes de las Cámaras.

- Por otro lado, el artículo 22.3 de la LODP señala la necesidad de que el Defensor del Pueblo, cuando entienda que un documento declarado secreto y no remitido por la Administración pudiera afectar de forma decisiva a la buena marcha de su investigación, lo pondrá en conocimiento de la Comisión Mixta. Esta mención no encuentra desarrollo en la Resolución por la que se regula el funcionamiento de la Comisión Mixta, por lo que cabe preguntarse, en el caso de que el Defensor del Pueblo actuara de esta manera, qué podría hacer la Comisión Mixta. Pues bien, la respuesta podría buscarse en la Resolución de la Presidencia del Congreso de los Diputados sobre Secretos Oficiales, de 11 de mayo de 2004, cuyo apartado segundo permite a las Comisiones recabar por conducto de la Presidencia de la Cámara que se informe a la misma sobre materias clasificadas. Lo que sucede es que según el apartado tercero de dicha Resolución, el Gobierno remitirá la información secreta (que es a la que se refiere el artículo 22.3 de la LODP) a un Diputado de cada Grupo Parlamentario designado por el Pleno de la Cámara por una mayoría de tres quintos. Asimismo, se establece la posibilidad de que el Gobierno solicite que la información sobre una materia clasificada se facilite en sesión secreta. De la regulación establecida en el resto de la Resolución se deduce, en nuestra opinión, un estricto deber de secreto para los Diputados que por estas vías puedan conocer información clasificada. Por ello, parece que la previsión del artículo 22.3 de la LODP simplemente servirá para lo que el propio artículo señala, es decir, para que el Defensor del Pueblo ponga en conocimiento de la Comisión Mixta que una de- 
terminada Administración se niega a enviarle un documento secreto. Poco o nada podrá hacer para ayudarle la Comisión Mixta porque, como hemos señalado, aunque algún Diputado de la Comisión Mixta pudiese acceder a información clasificada, la regulación establecida en la Resolución de de 11 de mayo de 2004 parece excluir cualquier posibilidad de que aquel Diputado pudiese poner tal información en conocimiento del Defensor del Pueblo.

- El artículo 49.2 del Reglamento del Congreso de los Diputados y el 49.3 del Reglamento del Senado señalan que la Comisión de Peticiones tiene el carácter de Comisión Permanente. De la regulación reglamentaria de ambas Cámaras se desprende, explícitamente en el caso del Congreso de los Diputados, e implícitamente en el caso del Senado (se deduce del artículo193 del Reglamento) la posibilidad de que las Comisiones de Peticiones de ambas Cámaras remitan algunas de las peticiones que hayan recibido al Defensor del Pueblo.

En conclusión, como hemos podido observar, la regulación aplicable a esta materia trata de asegurar un contacto permanente entre las Cortes Generales y el Defensor del Pueblo. Esto se intenta asegurar a través de los mecanismos que hemos venido analizando así como mediante declaraciones de carácter más general, como las incluidas en el artículo 3.1 del ROFDP, según el cual el Defensor del Pueblo únicamente es responsable de su gestión ante las Cortes Generales, o del artículo 8 c) de la misma norma, que atribuye al Defensor del Pueblo la función de mantener relación directa con las Cortes Generales a través del Presidente del Congreso de los Diputados y con ambas Cámaras a través de sus respectivos Presidentes. En todo caso, el que las normas que regulan la organización y funcionamiento del Defensor del Pueblo, que al fin y al cabo vienen a ser el desarrollo reglamentario de la LODP, hayan sido dictadas por las Cortes Generales, es también un hecho suficientemente revelador. En el último punto reflexionaremos sobre si este contacto llega a tener efectivamente la fluidez necesaria o si sería conveniente potenciarlo.

\section{REFLEXIONES FINALES}

Han pasado casi treinta años desde la entrada en vigor de la LODP y dieciocho desde la reforma de ésta. Las valoraciones sobre la institución se repiten habitualmente desde los ámbitos político, académico y social. No vamos a entrar aquí a realizar una valoración completa de la institución en general, aunque sí creemos que se puede afirmar que la opinión pública valora muy positivamente la existencia de la institución y la labor que realiza, hasta el punto de que parece un sentir general el deseo de que el Defensor del Pueblo tenga mayores competencias de las que actualmente ostenta. Para esto se realizan muy diferentes propuestas, como las que señala Soria- 
no ${ }^{33}$, que propone desde la publicación de las listas de incumplidores de las resoluciones del Defensor del Pueblo hasta medidas de índole más ejecutivo como dotar de legitimación procesal al Defensor del Pueblo (Gil-Robles y Gil-Delgado defiende este punto con especial énfasis en materia urbanísti$\left.\mathrm{ca}^{34}\right)$ o la obligación de los gestores públicos de cumplir las resoluciones del Defensor del Pueblo en plazos taxativos.

Estas propuestas responden en nuestra opinión a una creencia generalizada de que el Defensor del Pueblo, por su autonomía e independencia política, debe tener competencias que le permitan obligar a actuar a las Administraciones Públicas en un determinado sentido. Sin ánimo de realizar un debate en gran profundidad, en nuestra opinión estas propuestas olvidan que el Defensor del Pueblo es, ante todo, una magistratura de persuasión, y como tal debe actuar. Si el Defensor del Pueblo tuviese legitimación procesal activa en todos los órdenes jurisdiccionales o se pudiese exigir el cumplimiento de las resoluciones del Defensor del Pueblo, ya no estaríamos ante una magistratura de persuasión encargada de "supervisar", como señala la Constitución, la actividad del la Administración Pública, sino que nos encontraríamos ante un órgano netamente ejecutivo, lo cual excede de la naturaleza del instituto. En definitiva, creemos que el Defensor del Pueblo debe mantener esa posición de actuar como magistratura de persuasión, no sólo para supervisar a la Administración y recordarles sus obligaciones, sino también para crear opinión. Puede que haya a quien no le parezca suficiente, pero la auctoritas mediática del Defensor del Pueblo puede tener un efecto en la opinión pública mucho mayor que el que en un primer momento puede parecer. Esto, unido a su legitimación para interponer el recurso de inconstitucionalidad y el recurso de amparo, así como la posibilidad de comunicar al Ministerio Fiscal los casos en los que aprecie indicios de delito, dotan de todos los instrumentos al Defensor del Pueblo para cumplir su función constitucionalmente atribuida.

Es precisamente en el ejercicio de la función de persuasión, supervisión y creación de opinión pública donde tiene una importancia vital la relación entre el Defensor del Pueblo y las Cortes Generales. Al ser hoy el Parlamento el más importante foco de intercambio de opiniones y visiones políticas, el Defensor del Pueblo debería tener un acceso lo más fluido posible a la sede parlamentaria. Como señaló Alzaga ${ }^{35}$, los Informes del Defensor del Pueblo permiten "orientar tanto la labor crítica de la oposición como la tarea de gobierno hacia la superación de esas lacras, e incluso en ocasiones logra un influjo positivo y directo en la opinión pública”.

33 SORIANO DÍAZ, "Los puntos negros de la institución del Defensor del Pueblo", en Jueces para la Democracia, n. ${ }^{\circ} 35,1999$, págs. 8 y 9.

34 GIL-ROBLES y GIL-DELGADO, «El Defensor del Pueblo y el control parlamentario de la Administración", Anales de Derecho, Universidad de Murcia, número 10, 1987-1990, págs. 203.

35 ALZAGA, Derecho político español según la Constitución de 1978 volumen II, pág. 248, citado por SÁNCHEZ SAUDINÓS y PAJARES, en el "Comentario al artículo 32", en Comentarios...p. 801 
Aquí sí nos podemos plantear con más sosiego si este contacto entre ambas instituciones es suficiente o si es necesario aumentarlo y, en este caso, a través de qué vías.

Gil Robles y Gil-Delgado consideraba que las relaciones entre el Parlamento y el Defensor del Pueblo "son intensas, continuas y vitales" y que "los Informes del Defensor del Pueblo son instrumentos básicos sobre los que habrá de cimentarse el prestigio y el éxito de la institución, y para ello es vital que el Parlamento dedique una especial atención al análisis de los mismo, ${ }^{36}$. Este autor realizaba estas afirmaciones en los albores de la institución. Algunos años después volvía a insistir en que "es necesario potenciar la consolidación definitiva de las relaciones institucionales del Defensor del Pueblo... muy especialmente con las Cortes Generales", aunque ya reconocía que "el contacto del Defensor del Pueblo con las Comisiones ad hoc del Congreso y del Senado, ha estado casi reducido a las comparecencias anuales, durante las cuales es muy difícil un tratamiento sosegado y en profundidad de algunos temas ${ }^{37}$.

En el mismo sentido se pronunciaba también Sáinz Moreno ${ }^{38}$ poco antes de la entrada en vigor de la reforma de 1992, al señalar que uno de los problemas más reiteradamente planteados ha sido la insuficiencia de la relación entre el Defensor del Pueblo y las Cámaras, dado su carácter esporádico y la dificultad de examinar adecuadamente el gran número de temas que se plantean en el Informe del Defensor. De ahí que este autor concluya que sarece evidente, a la vista del resultado obtenido en los ocho años precedentes, que la actividad de la Comisión del Congreso y de la Comisión del Senado encargadas de relacionarse con el Defensor del Pueblo, ha sido manifiestamente insuficiente". La causa fundamental de esta situación, en opinión del ilustre Profesor, fue la creación de una Comisión específica en cada Cámara encargada de relacionarse con el Defensor del Pueblo, en lugar de establecer una permanente relación con cada Comisión parlamentaria competente en cada una de las materias en las que actúa el Defensor. Ya vaticinó Sáinz Moreno que la reforma que se avecinaba "no va a mejorar esta situación". Y desde luego, en lo que se refiere a la asiduidad de la presencia del Defensor del Pueblo en la Comisión Mixta, no se equivocó, y es que la creación de una Comisión Mixta de Relaciones con el Defensor del Pueblo no iba a venir a solucionar el problema de la citada escasa asiduidad.

La prueba de lo anterior es que, en lo que llevamos de IX Legislatura, la Comisión Mixta de Relaciones con el Defensor del Pueblo se ha reunido, aparte de la reunión de constitución, únicamente cuatro veces, dos para presentar los Informes Anuales de 2007 y 2008, otra para presentar un Informe Extraordinario sobre "Centros de protección de menores con trastorno de conducta y en difícil situación social" y una última para presentar el estudio monográfico sobre "Agua y ordenación del territorio" Por tanto, parece que la si-

36 GIL-ROBLES y GIL-DEGADO, El Control Parlamentario... pág. 311

37 GIL-ROBLES y GIL-DEGADO, El Defensor del Pueblo y el control... pág. 202

38 Op. cit., págs. 19 y ss. y 60. 
tuación no ha cambiado mucho desde el año 1992, y la realidad sigue siendo que la presencia del Defensor del Pueblo en las Cortes Generales es reducida y esporádica, y que por el formato de la tramitación y de los debates parlamentarios es muy difícil que se pueda hacer en el Parlamento un análisis en profundidad de los Informes del Defensor del Pueblo.

Con ello se reduce en gran medida el potencial de la labor de persuasión y de generación de opinión pública connatural a la auctoritas del Defensor del Pueblo, ya que se desaprovecha el foro privilegiado que es el Parlamento, tanto para el control de la actividad de la Administración Publica, como para realizar un análisis crítico que llegue a los ciudadanos de dicha actividad.

¿Qué se puede hacer para mejorar esto? Sáinz Moreno ${ }^{39}$ hace dos propuestas de gran interés que, en nuestra opinión, deberían ser atendidas: por un lado, que el examen del contenido material de los Informes del Defensor del Pueblo que se refieran a materias propias de las demás Comisiones de las Cámaras, se examinen en dichas Comisiones. La Comisión Mixta quedaría como un órgano centrado en prestarle auxilio institucional al Defensor del Pueblo y en controlar los posibles incumplimientos en los deberes del cargo; además, sería conveniente que el Defensor del Pueblo pueda poner en conocimiento de la Comisión Mixta las resistencias graves opuestas a su labor, para que, si la Comisión lo estima oportuno, convoque al causante del entorpecimiento a explicar en sede parlamentaria su actitud.

Soriano coincide en la primera propuesta al considerar necesaria "la exigencia de debatir en puntos del orden del día de sesiones parlamentarias (al menos, ante las Comisiones del Parlamento) las propuestas concretas del Defensor derivadas de sus Informes, Anuales o Extraordinarios, para que éstos no queden en mera información ${ }^{40}$,.

Estas medidas irían acompañadas de la necesaria publicidad que, como ya hemos señalado anteriormente, está asegurada por la regulación reglamentaria y su normativa de desarrollo.

Sin duda estas propuestas de reforma ayudarían a aumentar la intensidad de las relaciones entre el Defensor del Pueblo y las Cortes Generales. En nuestra opinión, también sería de gran utilidad que tanto los parlamentarios como el Defensor del Pueblo utilizasen lo más posible los mecanismos previstos en el artículo 200. 2 del Reglamento del Congreso de los Diputados, 10. 2 de la LODP y 11.2 del ROFDP, que, si se usan habitualmente y con lealtad, pueden hacer del Defensor del Pueblo un extraordinario colaborador de la actividad de control de las Cortes Generales y, por otro lado, pueden permitir al Defensor del Pueblo acudir o, al menos, estar más en contacto con la sede parlamentaria para analizar problemas concretos que pueden afectar a la vida diaria de los ciudadanos. Hasta ahora, la incidencia de la utilización de estos mecanismos ha sido escasísima. Como señala Bruñén ${ }^{41}$, por ejemplo, en

39 Op. cit., págs. 60 y ss.

40 Op. cit., pág. 8.

41 BRUÑÉN, "Comentario al artículo 10", en Comentarios... pág. 271. 
el año 2000, de las 26874 quejas recibidas por el Defensor del Pueblo, sólo 7 provenían del las Cortes Generales por la vía del artículo10.2 LODP. También sería muy adecuado que los Grupos Parlamentarios aprovechasen las indicaciones de los Informes del Defensor del Pueblo para presentar preguntas, interpelaciones, proposiciones no de ley o mociones e, incluso, iniciativas legislativas si consideran que en una materia señalada por el Defensor del Pueblo es necesaria una reforma legislativa.

El próximo año se cumplirán treinta desde la entrada en vigor de la LODP. Creemos que nadie puede negar la utilidad de la institución, sobre todo en un momento en el que la independencia política en las altas instancias estatales brilla por su ausencia. El Defensor del Pueblo debe seguir supervisando y persuadiendo, porque para eso se creó y, si lo considera necesario, cuestionando la constitucionalidad de una ley o protegiendo los derechos fundamentales a través del recurso de amparo. En lo que toca a su función de persuasión y supervisión, todo lo que ayude al Defensor del Pueblo no sobrará, y, por tanto, desde el momento en el que el ejercicio de esta función está íntimamente ligado a la relación del Defensor del Pueblo con las Cortes Generales, todo lo que contribuya a aumentar la intensidad de esta relación, será bienvenido. Existen mecanismos que pueden y deben ser utilizados para ello; los que falten, pueden y deben ser creados, siempre que se respete la naturaleza de la institución.

$$
* * *
$$

TITLE: The Ombudsman and the Parliament

ABSTRACT: Section 54 of the Spanish Constitution characterizes the Ombudsman as High Commissioner of the Spanish Parliament. From the above mentioned characterization a necessary relation stems between the Spanish Parliament and the Ombudsman, who will have to, for constitutional mandate, realize also to the Spanish Parliament of his labour. For it, it ensues from usefulness to analyze in what this relation makes concrete exactly beyond the juridical nature itself. From there, there is discovered that the overlap between both organs demonstrates fundamentally in the appointment and the cessation of the Ombudsman; in the presentation of the Reports of this one in parliamentary headquarters and in the possibilities of presence and contact of the Ombudsman with the Spanish Parliament; and, finally, in the material and buman resources of the Ombudsman, also dependents in different measure of the Spanish Parliament.

Resumen: El artículo 54 de la Constitución española caracteriza al Defensor del Pueblo como Alto Comisionado de las Cortes Generales. De dicha caracterización se deriva una necesaria relación entre el Parlamento español y el Defensor del Pueblo, que deberá también, por mandato constitucional, dar cuenta a las Cortes Generales de su labor. Por ello, resulta de utilidad analizar en qué se concreta exactamente esa relación más allá de la naturaleza jurídica misma. A partir de abi, se descubre que la imbricación entre ambos órganos se manifiesta fundamentalmente en el nombramiento y cese el Defensor del Pueblo; en la presentación de los Informes de éste en sede parlamentaria y en las posibilidades de presencia y contacto del Defensor del Pueblo con las Cortes Generales; $y$, finalmente, en los medios materiales y personales del Defensor del Pueblo, también dependientes en diferente medida de las Cortes Generales. 
KeY words: Ombudsman. Spanish Parliament. Appointment. Cessation. Annual Report. Extraordinary Report. Personnel. Economic Regime.

Palabras clave: Defensor del Pueblo. Cortes Generales. Nombramiento. Cese. Informe Anual. Informes Extraordinarios. Personal. Régimen Económico.

FECHA DE RECEPCIÓN: 02.07.2010. FeCHA DE ACEPTACIÓN: 28.07.2010. 